\title{
Conjoint moderate or high-risk alcohol and tobacco use among male out-patients in Thailand
}

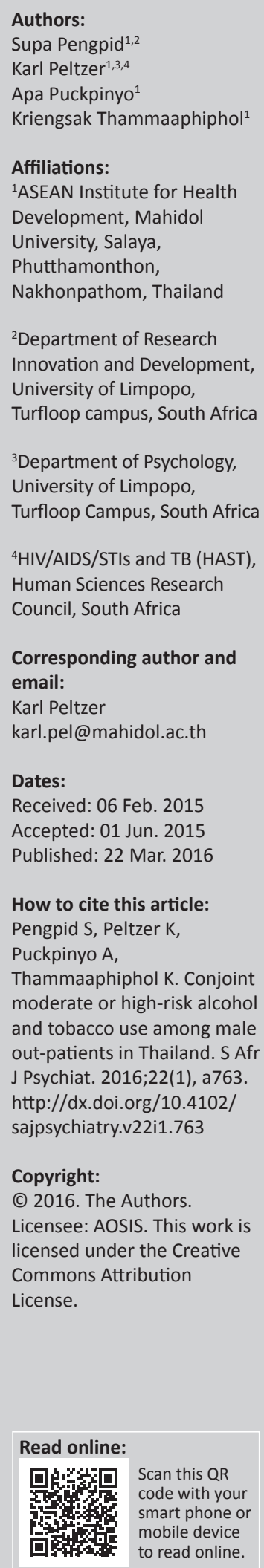

Objective: To better understand conjoint alcohol and tobacco use among male hospital out-patients, the purposes of this study were: (1) to assess the prevalence of conjoint use and (2) to determine the factors associated with the conjoint alcohol use and tobacco use.

Methods: In a cross-sectional survey, consecutive male out-patients from four district hospitals in Nakhon Pathom province in Thailand were assessed with the Alcohol, Smoking and Substance Involvement Screening Test (ASSIST), Hospital Anxiety and Depression Scale (HADS), selfreported chronic conditions and health-seeking behaviour. The sample included 2208 study participants, with a mean age of 36.2 years $(S D=11.7)$ and an age range of $18-60$ years.

Results: Overall, $34.5 \%$ of the male hospital out-patients were conjoint moderate or high-risk alcohol and tobacco users, and 31.1\% were moderate or high-risk alcohol or tobacco users. In multivariate analysis, younger age, having primary or less education, being separated, divorced or widowed, not having diabetes and not being obese were associated with conjoint moderate or high-risk alcohol and tobacco use.

Conclusion: High prevalence and several risk factors of conjoint alcohol and tobacco use were found among hospital male out-patients. The findings of this study call for dual-intervention approaches for both alcohol and tobacco.

\section{Introduction}

In Thailand the age-standardised prevalence of joint (daily) smoking and harmful or hazardous alcohol consumption in adults over 14 years of age was among men $10.0 \%$ and $10.3 \%$ in urban and rural areas, respectively, and among women $0.2 \%$ and $0.3 \%$ in urban and rural areas, respectively. ${ }^{1}$ In primary care patients in Thailand the most popular substances were tobacco and alcohol; ${ }^{2}$ in southern Thailand $90.5 \%$ were moderate or high-risk tobacco users and $44.6 \%$ were moderate or high-risk alcohol users. ${ }^{3}$ Among general hospital patients in Brazil the rate of comorbidity between alcohol use disorder and nicotine dependence was 3.6\%; in primary health care TB patients in South Africa it was $15.5 \%,{ }^{5}$ and the prevalence of concurrent alcohol and tobacco use in urban areas was, among men, $20.1 \%$ and in rural areas $14 \%$ in Sri Lanka. ${ }^{6}$ Previous studies ${ }^{7}$ have found that the synergistic health risks associated with alcohol and tobacco use are estimated to be $50 \%$ higher than the sum of their independent risks. There is a high association between nicotine and alcohol dependence. ${ }^{8,9,10}$ Compared to one specific substance use dependence, conjoint nicotine and alcohol dependence is more severe and has a more unfavourable course. ${ }^{9}$ Hurley et al.' $\mathrm{s}^{11}$ review showed that abuse of alcohol and nicotine (from tobacco products) can be attributed in part to genetics, the reward system and possibly the analgesic effects the drugs have.

Conjoint alcohol and tobacco use has been found to be associated with lower education, ${ }^{12,13}$ being male, ${ }^{12,13}$ younger age, ${ }^{14,15}$ and mental problems, including depression and anxiety disorders. ${ }^{12,13,16,17,18}$ Further, in general, people with a substance use disorder also have higher comorbid rates of mental disorders than vice versa. ${ }^{8,10,19}$ There is a lack of studies investigating conjoint alcohol and tobacco use among hospital male out-patients. Therefore, the aim of this study was exploring the prevalence of conjoint alcohol and tobacco use and alcohol or tobacco use and to determine the factors associated with conjoint alcohol and tobacco use and alcohol or tobacco use among male out-patients in Thailand.

\section{Method}

\section{Sample and procedure}

\section{Ethical considerations}

Four out of eight district hospitals in the Nakhon Pathom province in Thailand were randomly selected. In a cross-sectional survey consecutive male clients visiting the district hospital 
out-patient department were included in the study. A health care provider informed the patient about the study and referred the patient for participation if interested. A research assistant asked for permission and consent from patients attending the district hospital facility to participate in the study. Sampling occurred throughout all hours of hospital out-patient operation over a four-month period. We received ethical approval from the Mahidol University Research and Ethics Committee (COA. No. 2014/111.1804). The study was conducted from May 2014 to August 2014.

\section{Measures}

Tobacco and alcohol use were assessed with the Alcohol, Smoking and Substance Involvement Screening Test (ASSIST) ${ }^{20}$ A risk score is determined for each substance and is categorised as low-risk, moderate-risk or high-risk. ${ }^{20}$ In addition to tobacco and alcohol, other substances, according to the ASSIST, were also assessed. ${ }^{20}$ Further, patients were asked about their health care seeking behaviour for alcohol or tobacco use problems in the past three months. Those who were using alcohol and tobacco were asked about their needs to smoke in the context of drinking alcohol.

Socioeconomic characteristics: Age, gender, educational level, marital status, income, employment status and religious affiliation were assessed.

Chronic conditions: Major chronic conditions diagnosed by a health care provider, for example diabetes or hypertension, were assessed by self-report.

The Hospital Anxiety and Depression Scale (HADS) ${ }^{21}$ was used to assess anxiety (seven items) and depression (seven items). Scores of 8 or more were used as cut-offs for anxiety and depression. ${ }^{22}$ The HADS has good reliability and validity in Thailand. ${ }^{22,23}$ HADS subscales were internally reliable ( $\alpha$ depression: 0.74; $\alpha$ anxiety: 0.77).

\section{Data analysis}

The data were analysed using IBM SPSS (version 20.0) (4. $^{24}$ Frequencies, means and standard deviations were calculated to describe the sample. Associations of conjoint moderate or high-risk alcohol use and tobacco use, and moderate or high-risk alcohol use or moderate or high-risk tobacco use (without dual moderate or high-risk alcohol and tobacco use) were identified using logistic regression analysis. Following each univariate regression, multivariable regression models were constructed. Independent variables from the univariate analysis were entered into the multivariable model if significant at a level of $\mathrm{P}$ less than 0.05 . For each model, the $\mathrm{R}^{2}$ values are presented to describe the amount of variance explained by the multivariable model. Probability below 0.05 was regarded as statistically significant.

\section{Results}

Overall, $34.5 \%$ of the male hospital out-patients were conjoint moderate or high-risk alcohol and tobacco users, and $31.1 \%$ were moderate or high-risk alcohol or tobacco users (see Table 1). The use of other substances, as assessed with the ASSIST, found lifetime and past three months use as follows: $9.1 \%$ and $0.2 \%$ for cannabis, $0.7 \%$ and $0 \%$ for cocaine, $6.9 \%$ and $0.1 \%$ for amphetamine, $1.5 \%$ and $0 \%$ for solvents, $0.7 \%$ and $0.1 \%$ for diazepam or sleeping pills, $0.2 \%$ and $0 \%$ for hallucinogens, $0.8 \%$ and $0 \%$ for opium and $1.3 \%$ and $0.1 \%$ for other addictive substances. Other conditions that had been diagnosed included chronic obstructive pulmonary disease (COPD) (0.5\%), coronary artery disease $(1.0 \%)$, cardiac failure $(0.3 \%)$, cardiac arrhythmias $(0.6 \%)$, stroke $(0.5 \%)$, arthritis $(1.2 \%)$, cancer $(0.2 \%)$, thyroid disease $(0.7 \%)$, liver disease $(1.9 \%)$, kidney disease $(0.4 \%)$, epilepsy $(0.4 \%)$, stomach and intestinal disease $(4.4 \%)$, migraine or frequent headaches $(3.8 \%)$, and mental disorder $(0.7 \%)$.

The proportion of moderate or high-risk alcohol users was $44.2 \%$, and the proportion of moderate or high-risk tobacco users was $55.8 \%$. The proportion of moderate or high-risk tobacco users among moderate or high-risk alcohol users was $78.0 \%$, and $61.8 \%$ were moderate or high-risk alcohol users among the moderate or high-risk tobacco users. Compared to the older age group (35-60 years), the younger age group (18-34 years) was significantly more likely to engage in moderate or high-risk alcohol or tobacco use (see Table 2). The ASSIST alcohol use means score among conjoint moderate or high-risk alcohol and tobacco users was higher $(\mathrm{M}=17.0, \mathrm{SD}=4.3)$ than among moderate or high-risk alcohol users who were not moderate or high-risk tobacco users $(\mathrm{M}=16.8, \mathrm{SD}=4.3)$. Likewise, the ASSIST tobacco use means score among conjoint moderate or high risk alcohol and tobacco users was higher $(\mathrm{M}=20.1, \mathrm{SD}=5.4)$ than among moderate or high-risk tobacco users who were not moderate or high-risk alcohol users. Those with moderate or high-risk alcohol use had a significantly higher odds of anxiety symptoms (odds ratio (OR) 1.58; confidence interval (CI) 1.07-2.34). From the total sample of male outpatients, $2.5 \%$ reported to have consulted the self-help or quit line for their tobacco use problem, $1.2 \%$ a health facility and $0.3 \%$ had consulted a traditional or complementary medicine provider in the past three months. Regarding their alcohol problems, nobody had consulted a health care provider and $0.2 \%$ had consulted a traditional or complementary medicine provider in the past three months. The tendency or urge to smoke when drinking alcohol was felt by $38.3 \%$ of the study participants every time, $27.1 \%$ most of the time, $6 \%$ half of the time, $10.3 \%$ sometimes, and $18.3 \%$ never.

\section{Associations with moderate or high-risk alcohol or tobacco use}

In multivariate analysis in terms of socio-demographics, younger age $(\mathrm{OR}=0.69 ; \mathrm{CI}=0.53-0.90)$, having primary or less education $(\mathrm{OR}=0.46 ; \mathrm{CI}=0.32-0.66)$ and being separated, divorced or widowed $(\mathrm{OR}=2.61 ; \mathrm{CI}=1.53-4.44)$ were found to be associated with conjoint moderate or high-risk alcohol and tobacco use, while lower monthly income $(\mathrm{OR}=0.76$; $\mathrm{CI}=0.61-0.95)$ was associated with moderate or high-risk 
TABLE 1: Sample characteristics, moderate and high-risk alcohol or tobacco use by independent variables in male out-patients, 2014.

\begin{tabular}{|c|c|c|c|}
\hline Sociodemographic variables & Total $N(\%)$ & $\begin{array}{l}\text { Moderate or high-risk alcohol } \\
\text { and tobacco user } N(\%)\end{array}$ & $\begin{array}{l}\text { Moderate or high-risk alcohol } \\
\text { or tobacco user } N(\%)\end{array}$ \\
\hline All & 2208 & $765(34.5)$ & $686(31.1)$ \\
\hline \multicolumn{4}{|l|}{ Age in years } \\
\hline $18-25$ & $522(23.6)$ & $219(42.0)$ & $158(30.3)$ \\
\hline $26-34$ & $527(23.9)$ & $199(37.8)$ & $171(32.4)$ \\
\hline $35-44$ & $567(25.7)$ & $193(34.0)$ & $182(32.1)$ \\
\hline $45-60$ & $592(26.8)$ & $151(25.5)$ & $175(29.6)$ \\
\hline \multicolumn{4}{|l|}{ Education } \\
\hline Primary or less & $1157(52.4)$ & $410(35.4)$ & $356(30.8)$ \\
\hline Secondary & $849(38.5)$ & $307(36.2)$ & $276(32.5)$ \\
\hline Postsecondary & $202(9.1)$ & $45(22.3)$ & $54(26.7)$ \\
\hline \multicolumn{4}{|l|}{ Marital status } \\
\hline Never married & $571(25.9)$ & $193(33.8)$ & $169(29.6)$ \\
\hline Married or cohabiting & $1569(71.1)$ & $536(34.2)$ & $500(31.9)$ \\
\hline Religious affiliation: Buddhist (vs. others) & $2187(99.1)$ & $754(34.5)$ & $681(31.1)$ \\
\hline Employed (vs. unemployed or other) & $2038(92.5)$ & $713(35.0)$ & $634(31.1)$ \\
\hline \multicolumn{4}{|l|}{ Monthly income } \\
\hline$<10000$ Baht & $610(27.7)$ & $211(34.6)$ & $209(34.3)$ \\
\hline 10 000-15 000 Baht & $796(36.1)$ & $304(38.2)$ & $226(28.4)$ \\
\hline$>15000$ Baht & $797(36.2)$ & $245(30.7)$ & $249(31.2)$ \\
\hline \multicolumn{4}{|l|}{ Chronic conditions } \\
\hline Diabetes & $133(6.0)$ & $22(16.5)$ & $35(26.3)$ \\
\hline Hypertension & $286(13.0)$ & $71(24.8)$ & $85(29.7)$ \\
\hline Dyslipidemia & $191(8.7)$ & $46(24.1)$ & $58(30.4)$ \\
\hline Asthma & $107(4.9)$ & $44(41.1)$ & $31(29.0)$ \\
\hline Gout and other musculoskeletal conditions, such as chronic backache & $131(5.9)$ & $46(35.1)$ & $50(38.2)$ \\
\hline \multicolumn{4}{|l|}{ Mental problems } \\
\hline Anxiety & $107(4.8)$ & $46(43.0)$ & $36(33.6)$ \\
\hline Depression & $57(2.6)$ & $19(33.3)$ & 25 (43.9) \\
\hline
\end{tabular}

Source: Author's own work.

TABLE 2: Alcohol and tobacco user overlap.

\begin{tabular}{|c|c|c|c|c|c|c|c|}
\hline \multirow[t]{2}{*}{ Variable } & \multicolumn{2}{|c|}{ Total sample } & \multicolumn{2}{|c|}{ Age: $18-34$} & \multicolumn{2}{|c|}{ Age: $35-60$} & \multirow{2}{*}{$\begin{array}{l}\text { Statistic } \\
P \text {-value }\end{array}$} \\
\hline & $N$ & $\%$ & $N$ & $\%$ & $N$ & $\%$ & \\
\hline Moderate or high-risk alcohol users & 977 & 44.2 & 513 & 48.9 & 464 & 40.0 & $<0.001$ \\
\hline Moderate or high-risk tobacco users & 1233 & 55.8 & 652 & 62.2 & 581 & 50.1 & $<0.001$ \\
\hline Proportion of moderate or high-risk tobacco users among moderate or high-risk alcohol users & 762 & 78.0 & 418 & 81.5 & 344 & 74.1 & 0.006 \\
\hline Proportion of moderate or high-risk alcohol users among moderate or high-risk tobacco users & 762 & 61.8 & 418 & 64.1 & 344 & 59.2 & 0.077 \\
\hline Moderate or high-risk alcohol users or moderate or high-risk tobacco users & 686 & 31.1 & 329 & 31.4 & 357 & 30.8 & 0.776 \\
\hline
\end{tabular}

Source: Author's own work.

alcohol or tobacco use. In relation to chronic conditions, not having diabetes $(\mathrm{OR}=0.51 ; \mathrm{CI}=0.31-0.83)$ was in the multivariate analysis associated with conjoint moderate or high-risk alcohol and tobacco use. Finally, in terms of mental problems, depressive symptoms $(\mathrm{OR}=1.76$; $\mathrm{CI}=1.03-2.99)$ were associated with moderate or high-risk alcohol or tobacco use (see Table 3).

\section{Discussion}

This study found a high prevalence of conjoint alcohol and tobacco use in a large sample of male hospital out-patients in Thailand. Lower rates of comorbidity between alcohol use disorder and nicotine dependence were found among general hospital patients in Brazil, ${ }^{4}$ in primary health care TB patients in South Africa, ${ }^{5}$ and among men in the general population in Thailand ${ }^{1}$ and Sri Lanka. ${ }^{6}$ Similarly high rates of moderate or high-risk tobacco or alcohol use were found in a study among primary care attendees in southern Thailand. ${ }^{3}$ The study found that hardly any of the male out-patients had been seeking any type of health care service for their alcohol and tobacco use problem. This finding calls for screening and brief interventions, ${ }^{2}$ and providing dual-intervention approaches for both alcohol and tobacco.

Further, the study found, in agreement with other studies, ${ }^{9}$ that conjoint alcohol and tobacco users had higher ASSIST alcohol use and tobacco use scores than individuals who were tobacco or alcohol users only. Most participants in the study $(65.4 \%)$ had the urge to smoke when drinking all the time or most of the time. Simultaneous administration of alcohol and nicotine may cause additive or synergistic analgesic effects. ${ }^{11,25}$ Another contributory factor to co-use of alcohol and nicotine is likely the additive or synergistic 
TABLE 3: Association of sociodemographic and health variables and moderate or high-risk alcohol or tobacco use among male out-patients, 2014 ( $N=2180)$.

\begin{tabular}{|c|c|c|c|c|}
\hline \multirow[t]{2}{*}{ Sociodemographic variables } & \multicolumn{2}{|c|}{ Moderate or high-risk alcohol and tobacco user } & \multicolumn{2}{|c|}{ Moderate or high-risk alcohol or tobacco user } \\
\hline & UOR $(95 \% \mathrm{Cl})$ & $\operatorname{AOR}(95 \% \mathrm{Cl})^{\mathrm{a}}$ & UOR $(95 \% \mathrm{Cl})$ & $\operatorname{AOR}(95 \% \mathrm{Cl})^{\mathrm{b}}$ \\
\hline \multicolumn{5}{|l|}{ Age in years } \\
\hline $18-25$ & 1.00 & 1.00 & 1.00 & - \\
\hline $26-34$ & $0.84(0.66-1.08)$ & $0.82(0.63-1.06)$ & $1.11(0.85-1.44)$ & \\
\hline $35-44$ & $0.71(0.56-0.91)^{* *}$ & $0.69(0.53-0.90) * *$ & $1.09(0.84-1.41)$ & \\
\hline $45-60$ & $0.47(0.37-0.61 * * *$ & $0.45(0.33-0.61)^{* * *}$ & $0.97(0.75-1.25)$ & \\
\hline \multicolumn{5}{|l|}{ Education } \\
\hline Primary or less & 1.00 & 1.00 & 1.00 & - \\
\hline Secondary & $1.03(0.86-1.24)$ & $0.86(0.71-1.05)$ & $1.08(0.90-1.31)$ & \\
\hline Post-secondary & $0.52(0.37-0.74)^{* * *}$ & $0.46(0.32-0.66)^{* * *}$ & $0.82(0.59-1.15)$ & \\
\hline \multicolumn{5}{|l|}{ Marital status } \\
\hline Never married & 1.00 & 1.00 & 1.00 & \\
\hline Married or cohabiting & $1.02(0.83-1.04)$ & $1.25(0.99-1.58)$ & $1.11(0.90-1.37)$ & \\
\hline Separated/Divorced/Widowed & $1.85(1.11-3.06)^{*}$ & $2.61(1.53-4.44)^{* *}$ & $0.79(0.45-1.41)$ & \\
\hline Employed (vs. unemployed or other) & $1.31(0.93-1.86)$ & - & $1.07(0.76-1.51)$ & - \\
\hline \multicolumn{5}{|l|}{ Monthly income } \\
\hline$<10000$ Baht & 1.00 & - & 1.00 & 1.00 \\
\hline 10 000-15 000 Baht & $1.17(0.94-1.46)$ & & $0.76(0.61-0.96)^{*}$ & $0.76(0.61-0.95)^{*}$ \\
\hline$>15000$ Baht & $0.84(0.67-1.05)$ & & $0.87(0.70-1.09)$ & $0.87(0.69-1.09)$ \\
\hline \multicolumn{5}{|l|}{ Chronic conditions } \\
\hline Diabetes & $0.36(0.22-0.57)^{* * *}$ & $0.51(0.31-0.83)^{* *}$ & $0.78(0.53-1.16)$ & - \\
\hline Hypertension & $0.59(0.44-0.78)^{* * *}$ & $0.91(0.66-1.25)$ & $0.93(0.71-1.22)$ & - \\
\hline Dyslipidemia & $0.58(0.41-0.81)$ & - & $0.97(0.70-1.33)$ & - \\
\hline Asthma & $1.34(0.90-1.90)$ & - & $0.90(0.59-1.38)$ & - \\
\hline Gout and other musculoskeletal conditions, such as chronic backache & $1.03(0.71-1.49)$ & - & $1.40(0.97-2.01)$ & - \\
\hline \multicolumn{5}{|l|}{ Mental problems } \\
\hline Anxiety & $1.46(0.98-2.16)$ & - & $1.13(0.75-1.71)$ & - \\
\hline Depression & $0.95(0.54-1.65)$ & - & $1.76(1.04-2.99) *$ & $1.76(1.03-2.99)^{*}$ \\
\hline
\end{tabular}

Source: Author's own work.

$\mathrm{UOR}=$ unadjusted odds ratio; $\mathrm{AOR}=$ adjusted odds ratio $\mathrm{Cl}=$ confidence interval.

*** $P<0.001 ; * * P<0.01 ; * P<0.05$

aHosmer and Lemeshow chi-square $=5.22, p=0.733 ;$ Nagelkerke $R^{2}=0.06$.

bHosmer and Lemeshow chi-square $=9.19, p=0.327$; Nagelkerke $R^{2}=0.07$.

activation of the reward system..$^{11}$ This could mean that more intensive intervention strategies are needed, possibly integrating both alcohol reduction and tobacco cessation.

Several risk factors (socio-demographic and health factors, but not mental problems) were jointly associated with alcohol and tobacco use. In agreement with other studies, ${ }^{12,13,14,15}$ this study also found that lower education and younger age were associated with conjoint alcohol and tobacco use and lower monthly income was associated with moderate or high-risk alcohol or tobacco use. The finding that being separated, divorced or widowed was found to be associated with conjoint moderate or high-risk alcohol and tobacco use could be explained by substance use being a coping mechanism for their detrimental family situation. In relation to chronic conditions, not having diabetes was in the multivariate analysis associated with conjoint moderate or high-risk alcohol and tobacco use. It is plausible that male out-patients who have been diagnosed with diabetes may have reduced or stopped tobacco or alcohol use.

Unlike in some previous studies, $12,13,16,17,18$ this study did not find any association between mental problems (anxiety and depression) and joint alcohol and tobacco use. However, there was an association between depression and moderate or highrisk alcohol or tobacco use, and those with moderate or high-risk alcohol use had significantly higher odds of anxiety symptoms.

\section{Study limitations}

This study had several limitations. The study was crosssectional, so causal conclusions cannot be drawn. The investigation was carried out with male out-patients from four hospitals in one province, and inclusion of other hospitals could have resulted in different results. Hospital male out-patients are not representative of male adults in general, and the prevalence of the different alcohol and tobacco use practices and their risk factors may be different in other sectors of the population. Male patients consulting a hospital out-patient department with various physical illnesses may have a greater likelihood of smoking and alcohol drinking and this may thus be overrepresented in this sample. Another limitation of the study was that all the other information collected in the study was based on self-reporting. Self-reported data may be unreliable and thereby limit the validity of the associations drawn between conjoint substance use and other physical ailments.

\section{Conclusion}

High prevalence and several risk factors of conjoint alcohol and tobacco use were found among male hospital outpatients. The hospital out-patient setting may be a good place to carry out adequate dual-intervention approaches for both alcohol and tobacco use in men. 


\section{Acknowledgements}

Patients are thanked for participation in the study. Funding for this study was provided by the Thai Health Promotion Foundation.

\section{Competing interests}

The authors declare that they have no financial or personal relationships that may have inappropriately influenced them in writing this article.

\section{Authors' contributions}

S.P. (Mahidol University \& University of Limpopo) was the project leader. K.P. (Mahidol University, University of Limpopo \& Human Sciences Research Council) conducted the analysis, A.P. (Mahidol University) was the project manager, and K.T. (Mahidol University) performed some of the data collection. S.P. and K.P. wrote the manuscript and all contributed to and approved the final manuscript.

\section{References}

1. Aekplakorn W, Hogan MC, Tiptaradol S, Wibulpolprasert S, Punyaratabandhu P, Lim SS. Tobacco and hazardous or harmful alcohol use in Thailand: Joint prevalence and associations with socioeconomic factors. Addict Behav. 2008;33:503-14. http://dx.doi.org/10.1016/j.addbeh.2007.10.010

2. Assanangkornchai $S$, Balthip $Q$, Edwards JG; assistance of the ASSIST-SBI Development Co-investigators. Implementing the Alcohol, Smoking, Substance Involvement Screening Test and linked brief intervention service in primary care in Thailand. J Public Health. 2014;36:443-9. http://dx.doi.org/10.1093/pubmed/ fdu011

3. Nima P, Assanangkornchai S. Substance use pattern among primary health care attendees in southern Thailand. ASEAN J Psychiat. 2014;14:117-125.

4. Botega NJ, Mitsuushi GN, Azevedo RC, et al. Depression, alcohol use disorders and nicotine dependence among patients at a general hospital. Rev Bras Psiquiatr. 2010;32:250-6. http://dx.doi.org/10.1590/S1516-44462010005000016

5. Peltzer K. Conjoint alcohol and tobacco use among tuberculosis patients in public primary health care in South Africa. South Afr J Psychiatry 2014; 20:21-26. http:// dx.doi.org/10.7196/sajp.482

6. de Silva V, Samarasinghe D, Hanwella R. Association between concurrent alcohol and tobacco use and poverty. Drug Alcohol Rev. 2011;30:69-73. http://dx.doi. org/10.1111/j.1465-3362.2010.00202.x

7. Bien TH, Burge R. Smoking and drinking: A review of the literature. Int J Addict. 1990;25:1429-54. http://dx.doi.org/10.3109/10826089009056229
8. Farrell $\mathrm{M}$, Howes $\mathrm{S}$, Bebbington $\mathrm{P}$, et al. Nicotine, alcohol and drug dependence, and psychiatric comorbidity - Results of a national household survey. Int Rev Psychiatry. 2003;15:50-6. http://dx.doi.org/10.1080/0954026021000045949

9. Diehl A, Scherbaum N. Nicotine dependence as comorbidity of alcohol dependence - Epidemiology, etiology and therapy. Fortschr Neurol Psychiatr. 2008;76:14-20. http://dx.doi.org/10.1055/s-2007-980076

10. Subramaniam M, Abdin E, Vaingankar J, Phua AM, Tee J, Chong SA. Prevalence and correlates of alcohol use disorders in the Singapore Mental Health Survey. Addiction. 2012;107:1443-52. http://dx.doi.org/10.1111/j.1360-0443. 2012.03830.x

11. Hurley LL, Taylor RE, Tizabi Y. Positive and negative effects of alcohol and nicotine and their interactions: A mechanistic review. Neurotox Res. 2012;21:57-69. http://dx.doi.org/10.1007/s12640-011-9275-6

12. Horn K, Gao X, Williams J, Helmkamp J, Furbee M, Manley W. Conjoint smoking and drinking: $A$ case for dual-substance intervention among young emergency department patients. Acad Emerg Med. 2000;7:1126-1134. http://dx.doi. org/10.1111/j.1553-2712.2000.tb01262.x

13. Bonevski B, Regan T, Paul C, Baker AL, Bisquera A. Associations between alcohol, smoking, socioeconomic status and comorbidities: Evidence from the 45 and Up Study. Drug Alcohol Rev. 2014;33:169-76. http://dx.doi.org/10.1111/dar.12104

14. Anthony JC, Echeagaray-Wagner F. Epidemiologic analysis of alcohol and tobacco use. Alcohol Res Health. 2000;24: 201-8.

15. Falk DE, Yi HY, Hiller-Sturmhöfel $\mathrm{S}$. An epidemiologic analysis of co-occurring alcohol and tobacco use and disorders: Findings from the National Epidemiologic
Survey on Alcohol and Related Conditions. Alcohol Res Health. 2006;29:162-71.

16. Hertling I, Ramskogler K, Dvorak A, et al. Craving and other characteristics of the comorbidity of alcohol and nicotine dependence. Eur Psychiatry. 2005;20: 442-450. http://dx.doi.org/10.1016/j.eurpsy.2005.06.003

17. DeMartini KS, Carey KB. The role of anxiety sensitivity and drinking motives in predicting alcohol use: A critical review. Clin Psychol Rev. 2011;31:169-177. http://dx.doi.org/10.1016/j.cpr.2010.10.001

18. Kelly MM, Grant C, Cooper S, Cooney JL. Anxiety and smoking cessation outcomes in alcohol-dependent smokers. Nicotine Tob Res. 2013;15:364-375. http://dx.doi. org/10.1093/ntr/nts132

19. Jané-Llopis E, Matytsina I. Mental health and alcohol, drugs and tobacco: A review of the comorbidity between mental disorders and the use of alcohol, tobacco and illicit drugs. Drug Alcohol Rev. $2006 ; 25: 515-36$. http://dx.doi.org/10.1080/ 09595230600944461

20. Humeniuk RE, Henry-Edwards S, Ali RL, Poznyak V, Monteiro M. The Alcohol, Smoking and Substance Involvement Screening Test (ASSIST): Manual for use in primary care. Geneva: World Health Organization; 2010.

21. Zigmond AS, Snaith RP. The hospital anxiety and depression scale. Acta Psychiatr Scand. 1983;67:361-370. http://dx.doi.org/10.1111/j.1600-0447.1983.tb09716.x

22. Bjelland, I, Dahl, AA, Haug, TT, Neckelmann, D. The validity of the hospital anxiety and depression scale: An updated literature review. J Psychosom Res. 2002;52: 69-77. http://dx.doi.org/10.1016/S0022-3999(01)00296-3

23. Nilchaikovit $T$, Lortrakul $M$, Phisansuthideth U. Development of Thai version of Hospital and Depression Scale in cancer patients. J Psychiatr Assoc Thailand. 1996;41:18-30.

24. IBM SPSS [computer software]. Version 20.0. Armonk, NY: IBM Corp. 2011.

25. Yue J, Khokhar J, Miksys S, Tyndale RF. Differential induction of ethanolmetabolizing CYP2E1 and nicotine-metabolizing CYP2B1/2 in rat liver by chronic nicotine treatment and voluntary ethanol intake. Eur J Pharmacol. 2009;609:88-95. http://dx.doi.org/10.1016/j.ejphar.2009.03.015 